\title{
MODELO DA DINÂMICA INTERDISCIPLINAR DE RESPONSABILIDADE SOCIAL CORPORATIVA: CONTRIBUIÇÕES CONCEITUAIS E DELIMITAÇÃO TEÓRICA
}

\author{
MODEL OF INTERDISCIPLINARY DYNAMICS OF CORPORATE \\ SOCIAL RESPONSIBILITY: CONCEPTUAL CONTRIBUTIONS \\ AND THEORETICAL DELIMITATION
}

Data de submissão: 05/12/2013

Aceite: 20/05/2016

Evelize Welzel $^{1}$

Mônica Maria Mendes Luna² Maria Albertina Schmitz Bonin ${ }^{3}$ Cibele Barsalini Martins ${ }^{4}$

\section{RESUMO}

A literatura acerca da temática de negócios e sociedade apresenta conceitos correlatos ao de responsabilidade social corporativa (RSC) que muitas vezes são empregados como seus sinônimos. Isso ocorre, principalmente, no que se refere aos conceitos de responsividade social corporativa, ética empresarial e cidadania corporativa, apesar desses se diferenciarem em termos de conteúdo, abordagens e níveis em que são implantados nas empresas. A partir desta lacuna teórica, vislumbrou-se apresentar as principais contribuições de diversos campos do conhecimento na evolução do conceito de RSC para, a partir disso, propor um modelo teórico que represente a interdisciplinaridade entre conceitos-chave e, por fim, discutir a sua delimitação teórica, especialmente em relação ao conceito de cidadania corporativa. Nesse sentido, o presente estudo consiste numa pesquisa bibliográfica de natureza teórica. Como resultado, desenvolveu-se um modelo teórico da dinâmica interdisciplinar de RSC, projetando-se seus objetivos em nível dos negócios e na esfera societal. Por fim, construiu-se um quadro conceitual comparativo, mediante o qual se compara a abrangência e delimitação do conceito de RSC face ao conceito de cidadania corporativa e, posteriormente, em relação aos principais conceitos-chave da área de 'Business and Society'.

Palavras-chave: Responsabilidade Social Corporativa, Cidadania Corporativa, Business and Society.

\footnotetext{
1 Possui graduação e mestrado em Administração pela Universidade Federal de Santa Catarina, UFSC e doutorado em Administração Friedrich-SchillerUniversität Jena, FSU-JENA, Alemanha. Atualmente é professora do Departamento de Ciências da Administração, CAD, da Universidade Federal de Santa Catarina, UFSC. Florianópolis. Santa Catarina. Brasil. E-mail: ewelzel@hotmail.com

2 Possui graduação em Engenharia Civil pela Universidade Federal do Ceará, UFC, mestrado em Engenharia de Produção pela Universidade Federal de Santa Catarina, UFSC, mestrado em DEA en Logistique et Organisation pela Université Aix-Marseille II, AIX-MARSEILLE II, França, doutorado em Engenharia de Produção pela Universidade Federal de Santa Catarina, UFSC e pós-doutorado na Universidade de Bremen, Alemanha. Atualmente é Professora Associada da Universidade Federal de Santa Catarina. Florianópolis. Santa Catarina. Brasil. E-mail: monica.luna@ufsc.br

3 Possui graduação em Licenciatura em Matemática, graduação em Administração e mestrado em Administração pela Universidade Federal de Santa Catarina, UFSC. Atualmente é professor titular da Universidade do Vale do Itajaí. Biguacu. Santa Catarina. Brasil. E-mail: mbonin@univali.br 4 Possui graduação em Secretariado Executivo pela Universidade São Judas Tadeu, USJT, graduação em Administração, especialização em Qualidade nas Organizações, mestrado e doutorado em Administração pela Universidade Nove de Julho, UNINOVE. Atualmente está como Coordenadora do Programa de Pós-graduação em Administração do Centro Socioeconômico da UFSC, professora na Universidade Federal de Santa Catarina, UFSC. Florianópolis. Santa Catarina. Brasil. E-mail: cibelebm@uol.com.br
} 


\section{ABSTRACT}

The literature about the subject of business and society presents concepts related of corporate social responsibility (CSR) that are often employed as its synonyms. This occurs mainly regarding the concepts of corporate social responsiveness, business ethics and corporate citizenship, although these differ in terms of content, approaches and levels that are deployed in companies. From this theoretical gap, it was possible to present the main contributions of various fields of knowledge in the evolution of the concept of CSR, from addition, to propose a theoretical model that represents the interdisciplinarity between key concepts and, finally, to discuss its theoretical delimitation, especially in relation to the concept of corporate citizenship. In this sense, the present study consists in a bibliographic research of theoretical nature. As a result, it developed a theoretical model of the CSR's interdisciplinary dynamics, projecting its goals at the level of business and societal sphere. Finally, a comparative conceptual framework was constructed, upon which compares the scope and delimitation of the scope of CSR face to the concept of corporate citizenship and, subsequently, in relation to the main key concepts of 'Business and Society' area.

Keywords: Corporate Social Responsibility, Corporate Citizenship, Business and Society.

\section{INTRODUÇÃO}

Paralelamente à disseminação do conceito da Responsabilidade Social Corporativa (RSC), observa-se o surgimento de conceitos concorrentes como ética empresarial (EE), responsividade social corporativa (RSC2) e cidadania corporativa (CC). Esses têm princípios comuns, ou seja, primam pelo comprometimento ético, social e ecológico por parte das empresas. No entanto, a literatura não apresenta uma clara delimitação e/ou complementaridade entre esses conceitos, principalmente entre RSC e CC.

Em face desta realidade, esse artigo tem como objetivo apresentar as principais contribuições de diversos campos do conhecimento na evolução do conceito de RSC para, a partir disso, propor um modelo teórico que represente a interdisciplinaridade entre conceitos-chave e, por fim, discutir a sua delimitação teórica, especialmente em relação ao conceito de cidadania corporativa.

Assim, o presente estudo consiste numa pesquisa bibliográfica que o caracteriza como um trabalho essencialmente teórico (WHETTEN, 2003), elaborado a partir de uma pesquisa bibliográfica formal, discursiva e concludente (SEVERINO, 2000), com exposição argumentativa e interpretativa de diversos estudos realizados acerca dos conceitos e teorias sobre RSC (ZENISEK, 1979; WARTICK; COCHRAN, 1985; CARROLL, 1979, 1991; WOOD, 1991; ENDERLE; TAVIS, 1998; QUAZI; O'BRIEN, 2000; SCHWARTZ; CARROLL, 2003). Complementarmente, fez-se uma análise crítica-equiparativa das principais contribuições de diversos campos do conhecimento na evolução do conceito de RSC, com evidência em sua interdisciplinaridade e a delimitação entre os conceitos de RSC e CC. Entende-se ser uma metodologia adequada, tendo em vista a necessidade de apresentar as teorias subjacentes ao conceito de RSC, a relação deste com os principais conceitos da temática de negócios e sociedade para, por fim, proceder a sua delimitação.

$\mathrm{O}$ artigo está estruturado em três partes principais. Na primeira parte, faz-se uma discussão teórica das definições e modelos de RSC. Na parte seguinte, apresenta-se o modelo da dinâmica da RSC - framework - com o qual é possível representar o inter-relacionamento e o caráter complementar entre os conceitos-chave que dão forma ao complexo processo de implantação de RSC e seus conceitos concorrentes. Por fim, a partir da construção de um quadro conceitual, compara-se a abrangência e delimitação do conceito de RSC face ao conceito de cidadania corporativa e, posteriormente, em relação aos principais conceitos-chave da área de 'Business and Society'. 


\section{REFLEXÕES INTRODUTÓRIAS SOBRE O CONCEITO DE RESPONSABILIDADE SOCIAL CORPORATIVA (RSC)}

A responsabilidade social corporativa possui vários significados. Para alguns traduz a ideia de 'responsabilidade ou obrigação legal' (PRESTON; POST, 1981); o termo pode ainda ser compreendido como obrigação 'fiduciária' empresarial (FREEMAN, 1984); outra concepção do termo incorpora a noção de 'legitimidade' das empresas (DAVIS, 1973; WARTICK; COCHRAN, 1985); também expressa ideia de 'filantropia' (PORTER; KRAMER, 2002) e para outro grupo significa um 'comportamento ético empresarial' (SUCHANEK, 2003; HOMANN, 2004). Seu antônimo pode ser entendido pelos termos de 'irresponsabilidade social' ou 'inexistência de responsabilidade social' (ZENISEK, 1979).

A concepção do termo responsabilidade social corporativa pertence, na literatura acadêmica, à temática moderna do negócio e a sociedade (MATTEN et al., 2003; WADDOCK, 2004), onde é possível distinguir duas correntes principais no tocante ao seu direcionamento. A primeira pressupõe que a existência de uma empresa é permitida pela sociedade e, portanto, precisa ter legitimidade para existir (princípio da legitimidade) (SETHI, 1975; DAVIS; FREDERICK, 1985; WOOD, 1991). Concretamente, observa-se que há uma pressão exercida pela sociedade no intuito de forçar um maior engajamento das empresas nas questões sociais (JOYNER; PAYNE, 2002). Garrida e Melé (2004) denominam essa abordagem como 'constitucionalismo corporativo', a qual se fundamenta na ideia de que há uma codependência entre empresa e sociedade.

A segunda parte do princípio de que a RSC está interligada ao conceito de desenvolvimento sustentável, já que tem alicerce conceitual no tripé da sustentabilidade: as dimensões econômicas, ecológicas e sociais. Mais que isso, a RSC é a implementação da sustentabilidade na esfera corporativa (VAN MARREWIJK, 2003; RNE, 2006). Essas duas correntes não são excludentes, mas sim complementares e auxiliam na definição na RSC.

Nas palavras da comissão da comunidade europeia, a RSC pode ser entendida como um "conceito composto de fundamentos sociais e ambientais, ao qual a empresa adere livremente, visando servir e se relacionar de forma integrada com seus stakeholders" (EU-KOMMISSION, 2001, p.7, tradução livre). Essa é uma definição genérica do conceito de RSC e, portanto, apresenta várias possibilidades de entendimento e concretização do tema.

Fica clara nessa definição da EU a relevância das questões do meio ambiente, que associadas ao aumento da consciência ecológica por parte dos clientes e, por conseguinte, da exigência, em termos de qualidade geral das operações das empresas, representam o desafio do gerenciamento empresarial. Na prática, isso resultou na necessidade de outras formas de avaliação do desempenho das empresas, além dos balanços econômicos; surgiram assim os balanços sociais ou socioambientais. A figura 1 apresenta graficamente a evolução dessa realidade empresarial, bem como a respectiva resposta operacional das certificações. 


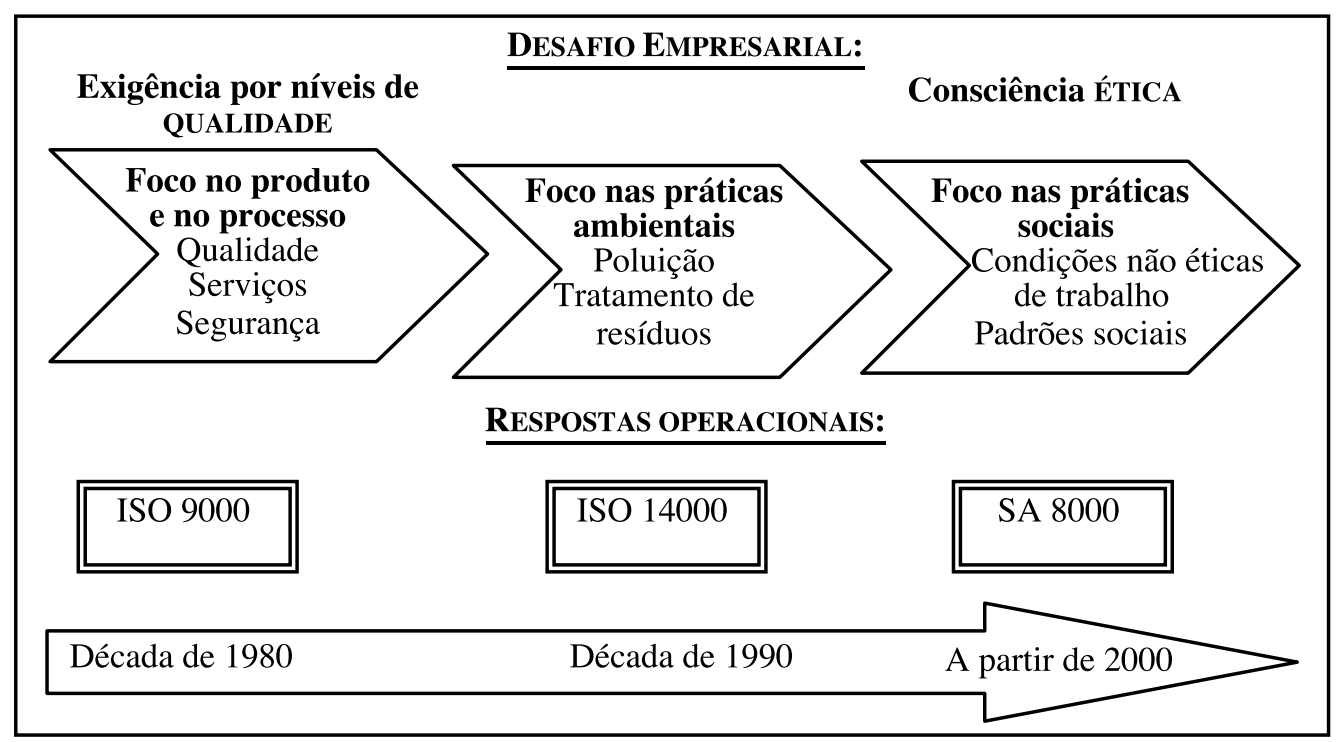

Figura 1: Evolução das iniciativas de certificação empresarial

Fonte: Adaptado de Kreikebaum et al. (2001, p.170)

Especialmente destaca-se aqui a difusão das certificações de cunho ambiental. Um dos motivos do crescimento das certificações ambientais emitidas se deve ao fato de que o fomento de atividades ecologicamente responsáveis pode trazer consigo uma diminuição nos custos operacionais da empresa, como pode ser constatado, por exemplo, a partir da introdução de estratégias para a economia de energia (HANSEN, 2004). De maneira geral, verifica-se um aumento no número de certificações ISO 14001 emitidas ao redor do mundo de praticamente 205\%, entre os anos de 2001 e 2005 (ISO SURVEY, 2005).

Contraditoriamente, a adesão a comportamentos ambientais sustentáveis requer o investimento no desenvolvimento de tecnologias limpas, o que pode influenciar direta e negativamente na competitividade das empresas no curto prazo. Em contrapartida, existem posicionamentos claros de que o desenvolvimento de tais tecnologias permite a obtenção de vantagens competitivas duradouras. Esse é o rumo escolhido pela comissão da comunidade europeia, a qual estabeleceu que o patrocínio de atividades ligadas à responsabilidade social corporativa é um dos alicerces estratégicos para que seja líder econômica da sociedade do conhecimento baseada em princípios da sustentabilidade (EU-KOMMISSION, 2001).

Outro padrão de certificação que 'atesta' o comprometimento social das empresas é a Social Accountability 8000 (SAI 8000). Entretanto, esse ainda não é um padrão amplamente implementado e aceito como o da ISO 14001. No entanto, expoentes do mundo empresarial alemão e europeu fazem parte do Advisory Board da SA 8000, o que incentiva na divulgação deste padrão, pois Ihe fornece credibilidade. Além disso, a ISO lançou um padrão sobre responsabilidade social em 2010, chamado ISO 26000 e, com isso, imagina-se que a adesão a padrões de certificação social tenda a crescer devido à popularização do conceito de responsabilidade social corporativa.

Em termos de modelos explicativos de RSC, existem 8 modelos principais. Zenisek (1979) definiu três perspectivas de RSC (operacional, ideológica e societal). No mesmo ano, Carroll (1979) definiu um modelo tridimensional sobre as categorias de RSC (econômica, legal, ética e discricionária), que foram reelaboradas em 1991 em forma de pirâmide, e a filosofia de responsividade social (reativa, defensiva, acomodada e proativa). 
O modelo piramidal sobre responsabilidade social corporativa idealizado por Carroll (1991) é tido até o momento como um modelo explicativo fundamental do tema. Com base nesse modelo a empresa possui quatro graus com categorias diferentes de responsabilidade social, a saber:

1. responsabilidade econômica - a empresa precisa gerar lucro;

2. responsabilidade legal - a empresa deve obedecer à lei;

3. responsabilidade ética - a empresa deve fazer o que é certo e agir sempre de forma correta e leal;

4. responsabilidade de ação discricionária - a empresa deve contribuir para a melhoria das condições da sociedade em geral, engajando-se em projetos sociais comunitários de cunho educacionais, culturais e esportivos (MATTEN e CRANE, 2005, p.167).

Os dois primeiros critérios são exigidos pela sociedade, o que Homann (2004) denominou de 'responsabilidade de ação' das empresas. O terceiro aspecto é esperado pela sociedade e o quarto é desejado por ela (CARROLL, 1991). A esses dois últimos critérios, Homann (2004, p.6) denominou de "ampliação da responsabilidade de ação" das empresas.

Num primeiro momento, esse modelo se apresenta como amplo e praticamente completo. No entanto, para Schneider (2004, p.22, tradução livre), o modelo de Carroll negligencia os preceitos básicos da RSC, mais precisamente o ecológico e o social, “(...) por ser construído a partir de uma lógica econômica dominante, onde esses aspectos surgem praticamente como preocupação secundária". Além disso, a autora salienta que a 'expectativa da sociedade' é um conceito arbitrário, pois a sociedade moderna, por definição, é fragmentada pela diversidade de pontos de vista, de interesses cada vez mais personalizados e divergentes, e, portanto, fica difícil esclarecer o que a expressão 'expectativa conjunta' representa.

Portanto, outro ponto a destacar é que o quarto critério do modelo piramidal de Carroll (1991) ficou mais conhecido e passou a ser utilizado, praticamente, como sinônimo de RSC. Isso se deve, em parte, ao fato de que deste critério surgiu o conceito de cidadania corporativa (CC), cujo conteúdo é basicamente filantrópico. Em razão disso, as empresas utilizam os resultados alcançados pelas ações sociais como forma de 'moeda' em momentos de crise (MATTEN et al., 2003; VAN MARREWIJK, 2003) como, por exemplo, quando a empresa é alvo de algum escândalo de corrupção, ou em caso de desastre ecológico, ou ainda quando há caso de demissão em massa. Nesses casos há uma desconfiança de que a empresa esteja apenas agindo em "interesse próprio", pois utiliza esses projetos como meio de publicidade, o que Matten et al. (2003, p.112) denominam de "utilização limitada" do conceito de cidadania corporativa.

Tendo por base os trabalhos de Carroll (1979), Wartick; Cochran (1985) definiram os principais desafios de RSC como sendo: a responsabilidade econômica, a responsabilidade pública e a responsividade social. Aqui os autores elaboraram um modelo de desempenho social corporativo onde as categorias de Carroll foram rebatizadas como príncipios de RSC e a filosofia de responsividade social em processos, sendo esses redefinidos da seguinte forma: reativa, defensiva, responsiva e interativa. Por último, os autores definiram que há a necessidade de incorporar essas duas categorias em um programa e/ou políticas de gestão social no contexto da empresa.

Partindo do trabalho de Wartick e Cochran (1985), Wood (1991) modificou o modelo de performance social corporativa ao remodelar os princípios em três níveis: institucional (legitimidade); organizacional (responsabilidade pública); individual (gerenciamento discricionário). Os processos também foram redefinidos em três temas: avaliação do ambiente onde a empresa atua; gestão dos stakeholders e; gestão social. A novidade desse modelo se refere à concretização da implementação das atividades de RSC, a saber: políticas sociais, programas sociais e impactos sociais. 
Outro modelo conceitual da responsabilidade social corporativa foi proposto por Enderle e Tavis (1998), onde são definidos três níveis éticos - de mínimo a idealista - para as principais dimensões de RSC (econômica, social e ambiental).

Especificamente sobre modelos explicativos da RSC, os autores Quazi e O'Brien (2000) desenvolveram o modelo bidimensional (Fig. 2). Esse modelo da RSC apresenta duas dimensões: (1) a amplitude da responsabilidade, entendida dentro de uma perspectiva que pode se estender entre extremos que vão de restrita a ampla; (2) os efeitos de ações de RSC, enquadrados em um extremo como benéfica para a empresa e, do outro, causadoras de custos.

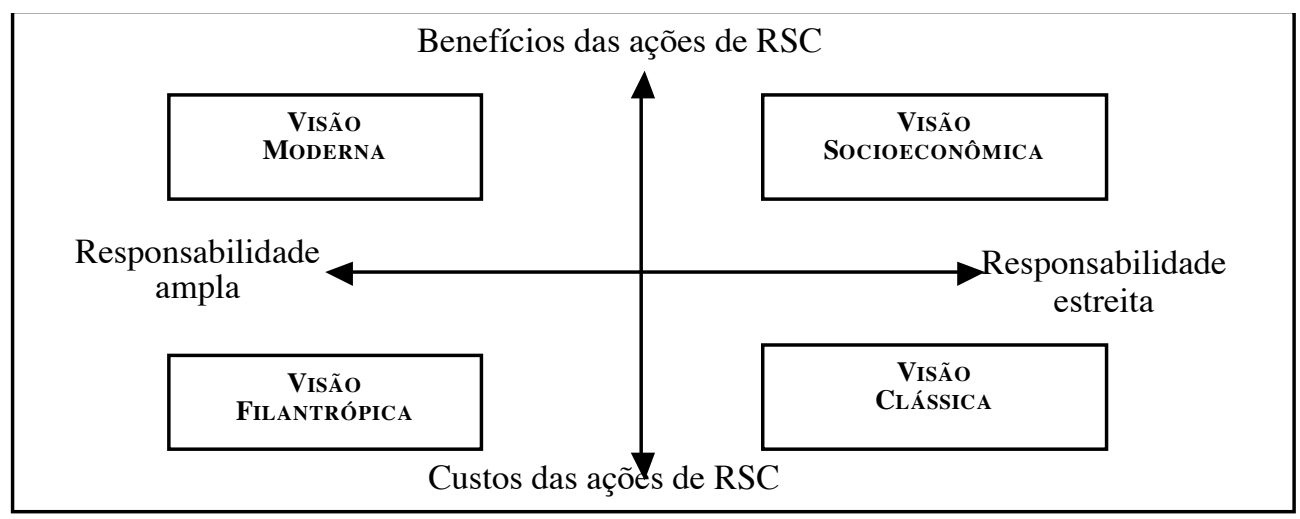

Figura 2: Modelo bidimensional de RSC

Fonte: Adaptado de Quazi e O’Brien (2000, p. 36)

A contribuição do modelo bidimensional está no fato de que a responsabilidade empresarial é avaliada a partir da perspectiva de seus custos, podendo ser categorizada em quadrantes distintos, a saber: (1) a visão clássica, que corresponde ao grau de responsabilidade econômica do Carroll e da posição defendida por Friedman (1988) de que a primeira responsabilidade da empresa é gerar lucro; (2) a visão socioeconômica é uma composição entre os graus da responsabilidade legal e ética de Carroll (1991), onde se entende que a empresa deva empreender ações sociais desde que tragam benefícios a ela, ou seja, agir em 'interesse próprio'; (3) a visão moderna, que contempla a combinação entre motivações éticas e os pressupostos da teoria dos stakeholders, tanto para garantir benefícios de curto e longo prazo; (4) a visão filantrópica, a qual corresponde à responsabilidade de ação discricionária de Carroll (1991).

Neste modelo a filantropia é vista como positiva, pois seus custos são tidos como 'investimento' na construção de relações com os stakeholders, bem como estratégia de melhoria da imagem corporativa. Com isso a empresa espera que a sociedade a favoreça devido as suas ações caritativas em prol da comunidade (QUAZI; O`BRIEN, 2000). Exatamente aí se observa a falha do modelo bidimensional, pois isso nada mais é do que agir em 'interesse próprio', como já é o caso da visão socioeconômica, mas com um 'revestimento' de altruísmo. Além disso, essa visão é enquadrada como 'responsabilidade ampliada', mas é baseada pura e simplesmente em ações caritativas, reforçando uma ideia de superficialidade da responsabilidade social corporativa.

Um terceiro modelo da RSC é apresentado por Schwartz e Carroll (2003), que se propõe a solucionar alguns problemas dos modelos anteriores. Primeiramente, ao definir como temas centrais da RSC a questão econômica, legal e ética, os autores quebram com a concepção equivocada de que a filantropia possui um lugar de destaque. Esta, por sua vez, pode ser observada em ações pontuais tanto dentro da dimensão ética ou econômica. Em segundo lugar, ao representar 
o modelo em um diagrama, os autores eliminam a errônea interpretação de que há uma hierarquia entre os temas centrais da RSC. Finalmente, esse modelo considera as possibilidades de combinações entre os temas centrais da RSC que resultou em sete categorizações das atividades das empresas e que, portanto, desfaz o modelo do 'ou', e trouxe consigo a possibilidade do 'e'. $\mathrm{O}$ modelo é apresentado na figura 3.

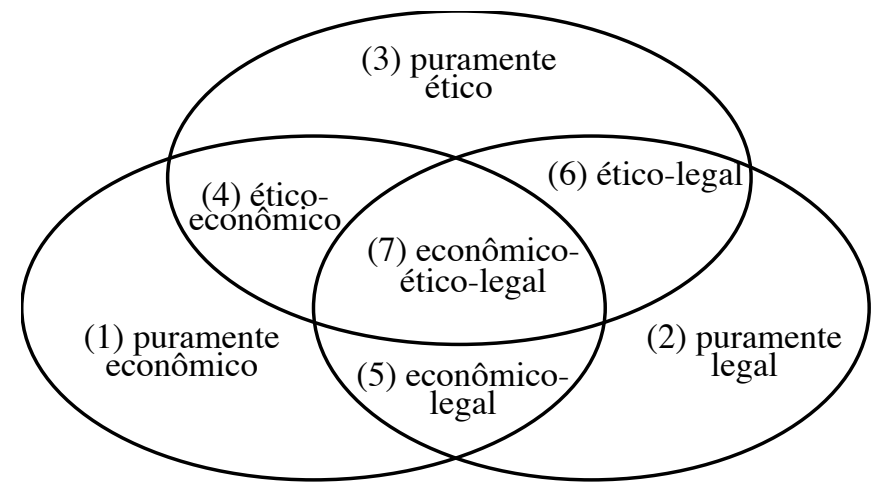

Figura 3: Modelo de três temas centrais de RSC

Fonte: Adaptado de Schwartz e Carroll (2003, p.519)

Entretanto, o modelo de Schwartz e Carroll apresenta algumas falhas. Nele são consideradas as atividades isoladamente e não há indicações de pressupostos, indicadores ou meios instrumentais com os quais uma empresa como um todo possa ser considerada, verificada e avaliada. Outro problema é o fato de que dificilmente uma atividade/ação ou empresa se encaixará na categoria 'puramente' ética, econômica ou legal, mas sim se imagina que haverá sempre uma tendência de ligação de no mínimo duas dimensões. O terceiro problema se refere ao fato de que a dimensão ambiental não está explicitada no modelo, mas sim é entendido como parte do tema ética, o que poderia levar erroneamente à conclusão de que seja um tema secundário. Em geral, esses modelos não abordam a questão central deste artigo de discutir como estão relacionados os conceitos-chave da temática de RSC, portanto, este é o tema apresentado a seguir.

\section{MODELO DA DINÂMICA INTERDISCIPLINAR DE RSC}

A concepção de RSC é, muitas vezes, entendida como sinônimo de outros conceitos (HANSEN; SCHRADER, 2005) ou esses são compreendidos como universos paralelos ou conceitos concorrentes (WADDOCK, 2004) que se ocupam com o mesmo fenômeno social. Garriga e Melé (2004) sintetizaram as várias teorias da temática da responsabilidade social corporativa em quatro grupos descritos no quadro 1.

\begin{tabular}{|c|c|c|}
\hline Teoria & Características & Exemplos \\
\hline $\begin{array}{c}\text { Instru- } \\
\text { mentais }\end{array}$ & $\begin{array}{c}\text { as ações sociais são instrumentos de criação de va- } \\
\text { lor econômico para a empresa }\end{array}$ & $\begin{array}{c}\text { Estratégias para a base da pirâmide, } \\
\text { cause-related marketing }\end{array}$ \\
\hline Políticas & $\begin{array}{c}\text { a empresa utiliza sua força de forma responsável de } \\
\text { modo a influenciar mudanças no nível político }\end{array}$ & $\begin{array}{c}\text { Teoria do contrato social integrado, ci- } \\
\text { dadania corporativa. }\end{array}$ \\
\hline $\begin{array}{c}\text { Integrati- } \\
\text { vas }\end{array}$ & $\begin{array}{c}\text { a empresa procura incorporar as demandas sociais } \\
\text { às suas estratégias }\end{array}$ & $\begin{array}{c}\text { Gestão dos stakeholders, performance } \\
\text { social corporativa }\end{array}$ \\
\hline Éticas & $\begin{array}{c}\text { a empresa procura melhorar as condições da socie- } \\
\text { dade orientando-se por princípio éticos }\end{array}$ & $\begin{array}{c}\text { Direitos universais, desenvolvimento } \\
\text { sustentável, the common good }\end{array}$ \\
\hline
\end{tabular}

Quadro 1: Abordagens teóricas acerca da RSC

Fonte: Adaptado de Garriga e Melé (2004, p.63-64) 
Para os autores, na prática, toda teoria relativa à temática da RSC possui em si uma vinculação com as questões de geração de lucro, desempenho político, demandas sociais e valores éticos, mas abordam esses temas de forma diferenciada e com pesos distintos (GARRIGA; MELÉ, 2004). Em função disso, faz-se necessário o estudo individual de cada conceito-chave para então conceber a sua interligação. No quadro 2 são apresentados os conceitos-chave na evolução da RSC.

\begin{tabular}{|c|c|c|c|}
\hline Conceito-chave & Definição/Características & Principais Autores & $\begin{array}{c}\text { Principal } \\
\text { Abordagem }\end{array}$ \\
\hline \multirow{2}{*}{$\begin{array}{l}\text { Responsabilidade } \\
\text { Social } \\
\text { Corporativa } \\
\text { (RSC1) }\end{array}$} & \multirow{2}{*}{$\begin{array}{l}\text { Basicamente define os princípios, as } \\
\text { formas e os motivos pelos quais as em- } \\
\text { presas devem ser responsáveis (RODRI- } \\
\text { GUEZ et al., 2002, p.135) }\end{array}$} & $\begin{array}{l}\text { Bowen (1953); Frederick } \\
\text { (1960); Davis (1967; 1973); } \\
\text { Preston e Post (1975) } \\
\end{array}$ & Normativa \\
\hline & & Carroll (1979); Jones (1980) & Descritiva \\
\hline \multirow{2}{*}{$\begin{array}{l}\text { Responsividade } \\
\text { Social } \\
\text { Corporativa } \\
\text { (RSC2) }\end{array}$} & \multirow{2}{*}{$\begin{array}{l}\text { "(...) significa que as empresas devem } \\
\text { tomar a iniciativa agindo antecipada- } \\
\text { mente na proposição de políticas que } \\
\text { atendam seus públicos externos" (WA- } \\
\text { DDOCK, 2004, p.16, tradução livre) } \\
\text { "(...) propõe a resposta das empresas } \\
\text { frente às demandas sociais" (RODRI- } \\
\text { GUEZ et al., 2002, p.135, tradução livre) }\end{array}$} & $\begin{array}{l}\text { Ackerman (1973; 1975); Bla- } \\
\text { cke (1974): Ackerman e Bauer } \\
\text { (1976); Sethi (1979); Strand } \\
(1983)\end{array}$ & Descritiva \\
\hline & & Preston e Prost (1975) & Mista \\
\hline \multirow[b]{2}{*}{$\begin{array}{l}\text { Performance } \\
\text { Social } \\
\text { Corporativa } \\
\text { (PSC) }\end{array}$} & \multirow{2}{*}{$\begin{array}{l}\text { "São as formas de mensurar a responsa- } \\
\text { bilidade social em termos de sua eficácia, } \\
\text { no intuito de relacionar medidas sociais e } \\
\text { financeiras" (MATTEN et. al., 2003, p.110, } \\
\text { tradução livre). “(...) incorpora as princi- } \\
\text { pais contribuições da RSC e RSC2 e tem } \\
\text { como foco os resultados dessas no com- } \\
\text { portamento organizacional” (RODRIGUEZ } \\
\text { et al., 2002, p.135, tradução livre) }\end{array}$} & $\begin{array}{l}\text { Sethi (1979); Carroll (1979); } \\
\text { Swanson (1999) }\end{array}$ & $\begin{array}{c}\text { Normativa e } \\
\text { Descritiva }\end{array}$ \\
\hline & & $\begin{array}{l}\text { Wartick e Cochran (1985); } \\
\text { Wartick (1988); } \\
\text { Wood (1991); Clarkson } \\
\text { (1995); Swanson (1995) }\end{array}$ & Mista \\
\hline $\begin{array}{l}\text { Gestão } \\
\text { Sustentável } \\
\text { (GS) }\end{array}$ & $\begin{array}{l}\text { Tem como premissa básica o reconhe- } \\
\text { cimento de que o mundo corporativo é } \\
\text { parte integrante de um sistema social e } \\
\text { natural. Isso tem duas implicações dramá- } \\
\text { ticas: a aceitação da escassez dos recursos } \\
\text { naturais e a noção de que as empresas e a } \\
\text { sociedade são corresponsáveis pela utiliza- } \\
\text { ção e desenvolvimento dos recursos (RO- } \\
\text { DRIGUEZ et al., 2002, p.137, tradução livre) }\end{array}$ & $\begin{array}{l}\text { WECD (1987) } \\
\text { Müller-Christ } \quad \text { (2004) Hüls- } \\
\text { mann (2004) }\end{array}$ & Mista \\
\hline $\begin{array}{l}\text { Governança Cor- } \\
\text { porativa (GC) }\end{array}$ & $\begin{array}{l}\text { "Refere-se ao sistema pelo qual socie- } \\
\text { dades empresariais são dirigidas e con- } \\
\text { troladas, envolvendo o relacionamento } \\
\text { entre acionistas, conselhos e diretoria } \\
\text { das empresas" (RABELO e VASCONCE- } \\
\text { LOS, 2002, p.322, tradução livre) }\end{array}$ & $\begin{array}{l}\text { Hart }(1990,1995) \\
\text { La Porta et al. }(1997,1998, \\
1999)\end{array}$ & Normativa \\
\hline \multirow{4}{*}{$\begin{array}{l}\text { Teoria dos } \\
\text { Stakeholders }\end{array}$} & \multirow{4}{*}{$\begin{array}{l}\text { "É a identificação concreta com base em } \\
\text { princípios de legitimidade e priorização } \\
\text { dos grupos sociais para com os quais a } \\
\text { empresa possui responsabilidades e que } \\
\text { ao mesmo tempo influenciam as deci- } \\
\text { sões corporativas" (DONALDSON e PRES- } \\
\text { TON, 1995, p.110-111, tradução livre) }\end{array}$} & Carroll (1989) & Normativa \\
\hline & & $\begin{array}{l}\text { Brenner e Cochran (1991); } \\
\text { Mitchell et. al. (1997) }\end{array}$ & Descritiva \\
\hline & & $\begin{array}{l}\text { Freeman (1984; 1999); Jo- } \\
\text { nes (1995) }\end{array}$ & Instrumental \\
\hline & & \begin{tabular}{|l|} 
Donaldson; Preston (1995); \\
Jones e Wicks (1999); \\
Clarksson (1995) \\
\end{tabular} & Mista \\
\hline
\end{tabular}




\begin{tabular}{|c|c|c|c|}
\hline Conceito-chave & Definição/Características & Principais Autores & $\begin{array}{c}\text { Principal } \\
\text { Abordagem }\end{array}$ \\
\hline $\begin{array}{l}\text { Responsabilidade } \\
\text { Corporativa (RC1) }\end{array}$ & $\begin{array}{l}\text { "Representa o grau de (ir)responsabili- } \\
\text { dade observada a partir das estratégias } \\
\text { e práticas de uma empresa, tais como } \\
\text { os seus impactos nos stakeholders e no } \\
\text { meioambiente"(WADDOCK, 2004, p.10, } \\
\text { tradução livre) }\end{array}$ & Donaldson; Dunfee (1994) & Mista \\
\hline $\begin{array}{l}\text { Reputação Cor- } \\
\text { porativa (RC2) }\end{array}$ & $\begin{array}{l}\text { "(...) engloba a percepção geral que os } \\
\text { stakeholders externos e internos têm } \\
\text { sobre aspectos empresariais como es- } \\
\text { tratégias, práticas, produtos e compro- } \\
\text { metimento social, que podem ser men- } \\
\text { suradas com base em uma ampla gama } \\
\text { de medidas, tanto financeiras quanto } \\
\text { subjetivas. Essas envolvem critérios que } \\
\text { tratam as relações com os stakeholders } \\
\text { e o meioambiente" (WADDOCK, 2004, } \\
\text { p.12, tradução livre) }\end{array}$ & $\begin{array}{l}\text { Fombrun; Shanley (1990); } \\
\text { Wartick (1992; 2002); Form- } \\
\text { brun (1998) }\end{array}$ & Mista \\
\hline $\begin{array}{l}\text { Retidão Social } \\
\text { Corporativa } \\
\text { (RSC3) ou Ética } \\
\text { Empresarial (EE) }\end{array}$ & $\begin{array}{l}\text { "(...) envolve um penetrante senso de } \\
\text { retidão, de respeito e de preceitos hu- } \\
\text { manitários que devem estar contidos } \\
\text { nos princípios e valores éticos funda- } \\
\text { mentais da empresa, de forma a refletir } \\
\text { suas políticas e decisões centrais" (WA- } \\
\text { DDOCK, 2004, p.19, tradução livre) } \\
\end{array}$ & $\begin{array}{l}\text { Donaldson (1992; 1996); } \\
\text { Liedtka (1998) }\end{array}$ & Mista \\
\hline \begin{tabular}{|c|} 
Cidadania Cor- \\
porativa (CC) ou \\
Corporate Citi- \\
zenship/ Business \\
Citizenship \\
\end{tabular} & $\begin{array}{l}\text { Envolve uma perspectiva ampla dos di- } \\
\text { reitos e deveres empresariais (WADDO- } \\
\text { CK, 2004, p.10, tradução livre) }\end{array}$ & $\begin{array}{l}\text { Wood e Logsdon (2001); } \\
\text { Marsden (2000); Marsden e } \\
\text { Andrioff (1998); Mclntosh, } \\
\text { Leipziger, Jones e Coleman } \\
\text { (1998); Waddock (2002; } \\
\text { 2004) }\end{array}$ & Mista \\
\hline
\end{tabular}

Quadro 2: Conceitos-chave na evolução do conceito de RSC

Fonte: Elaboração própria a partir da adaptação dos estudos de Waddock (2004) e Rodriguez et al. (2002)

Frederick (1987) subdividiu a RSC em três conceitos distintos. A Responsabilidade Social Corporativa (RSC1), objeto de estudo no presente artigo, compreende um conceito amplo e com um caráter filosófico do comportamento organizacional. A Responsividade Social Corporativa (RSC2) consiste em um conceito mais pragmático a partir do qual a empresa deveria ter uma postura prospectiva e proativa em relação às demandas sociais (SETHI, 1975). Finalmente, Frederick (1987) apresenta o conceito de Retidão Social Corporativa (RSC3), ou ética empresarial (EE), com a qual a responsabilidade empresarial é tratada a partir de uma perspectiva predominantemente normativa baseada em valores morais.

O debate sobre o conceito de ética empresarial, de um lado, vem acompanhado do levantamento de atividades (abordagem descritiva) e obrigações (abordagem normativa) que devem ser observados pela empresa e que não ficam restritas ao seu desempenho econômico (SCHNEIDER, 2004). Por outro lado, uma das principais funções da ética empresarial é propiciar "a discussão crítica das regras e normas dos integrantes de uma empresa - desde a sua diretoria, a média gerência e os funcionários - e dos diretamente afetados por essa empresa" (KREIKEBAUM, 2000, p.489, tradução livre). Portanto, a ética empresarial pode, inclusive, auxiliar no desenvolvimento das atividades do gestor e até na diminuição dos custos da empresa.

Com isso, observa-se que a ética não se restringe à função de 'amansar' a economia (paradigma de domesticação) (HOMANN, 2004). Isso porque a aplicação de diretrizes éticas pode trazer economias no custo de transação, já que as regras econômicas baseadas em preceitos éticos claros amenizam perdas e desgastes desnecessários no desenvolvimento eficiente da ati- 
vidade econômica (KREIKEBAUM, 2000). Nesse sentido, a elaboração e comunicação de códigos de conduta por parte de várias indústrias foram percebidas como os primeiros resultados da chamada onda de 'consciência ética' (WADDOCK, 2004).

Os conceitos apresentados no Quadro 2 podem ser vistos, num primeiro momento, como concorrentes. No entanto, eles são entendidos aqui como diferenciados, pois tratam de aspectos específicos que dão forma ao conceito interdisciplinar de RSC (Figura 4) e auxiliam na implementação de estratégias cujo conteúdo trata das demandas sociais.

A constatação da existência de numerosos e diferenciados conceitos inter-relacionados tem consequências ambivalentes. Por um lado, confunde e atrapalha a compreensão do significado de cada conceito, bem como a delimitação e diferenciação entre eles. Além disso, em uma visão pragmática, dá margem a interpretações semelhantes de níveis de responsabilidade social corporativa, os quais na verdade se baseiam em estratégias de graus distintos. Por outro lado, o surgimento de variados conceitos na área que trata dos negócios e sociedade pode ser entendido como um indicador do crescimento do interesse público do envolvimento empresarial nas questões sociais (WADDOCK, 2004).

A gestão dos stakeholders é parte integrante do desenvolvimento e entendimento do conceito de RSC. Esta teoria foi proposta por Freeman (1984) e preconiza que as empresas afetam, positiva ou negativamente, diversos grupos no ambiente onde estão inseridas, da mesma forma que podem ser favorecidas ou prejudicadas por esses grupos. Portanto, há uma ampliação do espectro de ação das empresas, que passam a ser responsáveis não apenas pela geração de lucros para os acionistas, mas sim pelas expectativas de um grupo maior, os chamados stakeholders.

Em função do tipo de relacionamento entre as empresas e cada um desses grupos, no que se refere à sua influência e relevância para o funcionamento e existência da empresa, esses se diferenciam e subdividem-se em stakeholders primários - como acionistas, investidores, funcionários, clientes, fornecedores, governo, parceiros estratégicos e comunidade local (CLARKSON, 1995) -, e secundários - um exemplo clássico é a mídia (MAIGNAN; FERRELL, 2000).

Visto que esta taxonomia é simplificada, Rodriguez et al. (2002) sugerem uma subdivisão, a qual dá origem a outros três tipos ou níveis de classificação dos stakeholders: (1) consubstanciais - englobam os grupos que são essenciais para o desenvolvimento das atividades elementares da empresa (acionistas e investidores, funcionários e parceiros estratégicos); (2) contratuais - grupos que formalmente façam negócios com a empresa (fornecedores, instituições financeiras e clientes); (3) contextuais - grupos que são importantes na construção e manutenção da credibilidade da empresa pois desenvolvem um trabalho de controle externo das suas atividades (governo, ONG, mídia).

Constata-se, portanto, que não é possível classificar de forma genérica e definitiva cada um dos stakeholders para todas e quaisquer empresas. Em termos práticos, cada empresa precisa avaliar o seu negócio, o ambiente em que atua e, a partir disso, definir que tipo de relação tem com cada grupo, bem como qual a importância destes para a sua sobrevivência. Uma taxonomia simplificada, mas que deixa claro o papel desenvolvido pelos stakeholders no desenvolvimento das estratégias das empresas, é o de stakeholders internos e externos (NAOR, 1982; KREIKEBAUM et al., 2001). Os stakeholders internos compreendem aqueles grupos sobre os quais as empresas possuem um alto grau de controle, como, por exemplo, os funcionários da empresa. Já os externos são difíceis de controlar. Nesse caso as empresas criam estratégias para influenciá-los, o que leva à necessidade de a empresa criar laços de relacionamento e confiança com esses atores no meio em que atua. Uma estratégia nessa direção consiste no engajamento comunitário, tema que será abordado na seção 5 deste artigo. 
A aceitação da teoria da gestão dos stakeholders se baseia nos argumentos descritivos - os gestores precisam determinar quais os grupos sociais mais importantes e que devem ser considerados pela estratégia da empresa e não a sociedade como um todo - e instrumental de sua implementação - retornos que a empresa pode ter ao se comportar de modo esperado pela sociedade (MATTEN et al., 2003). No entanto, Donaldson e Preston (1995) indicam que o enfoque principal dessa teoria está no argumento normativo - a empresa tem uma obrigação moral para com seus stakeholders (MATTEN et al., 2003; WADDOCK, 2004).

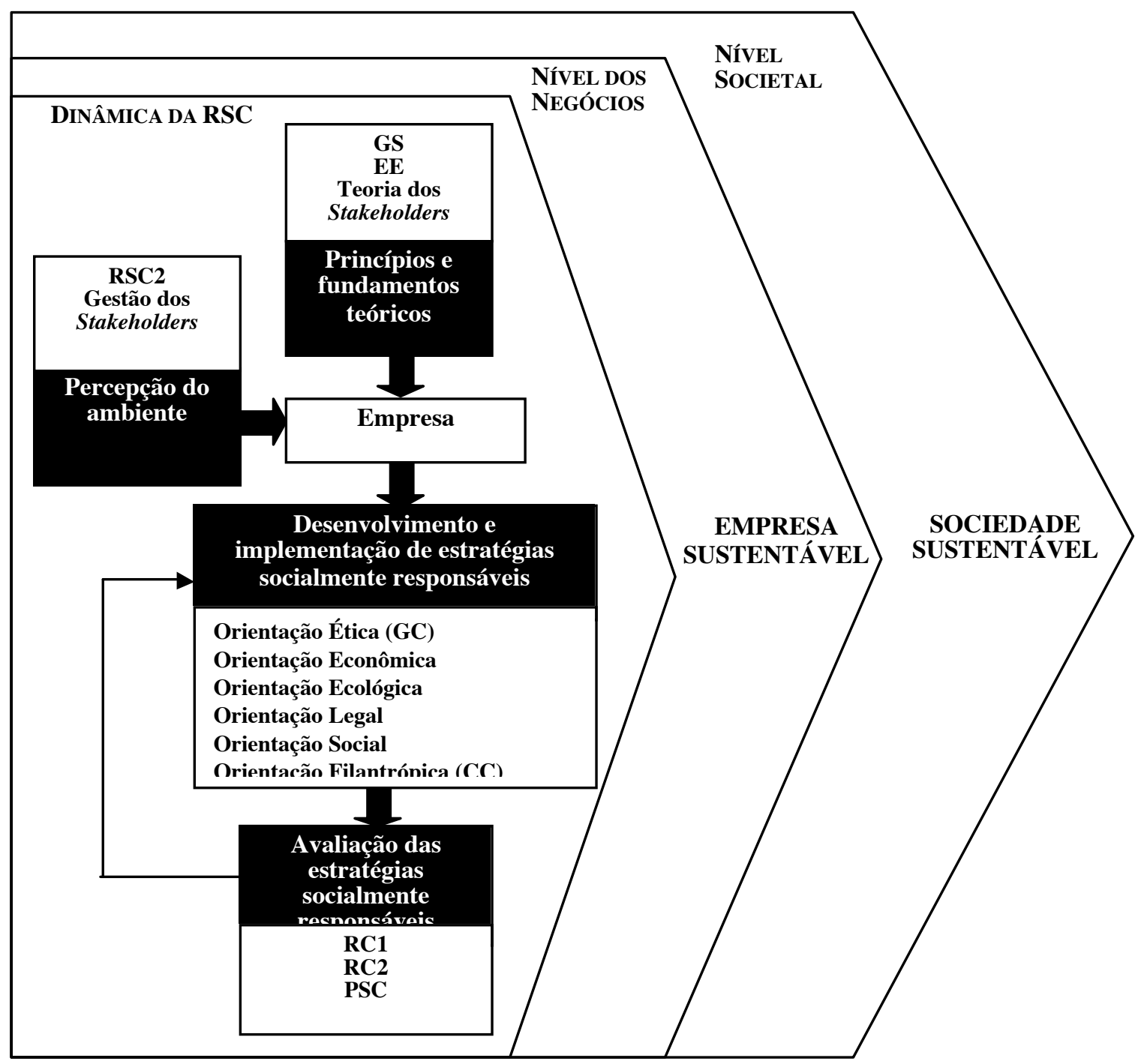

Figura 4: Modelo da dinâmica interdisciplinar de RSC Fonte: Elaboração própria

Na figura 4 observa-se que o conceito de RSC é construído a partir dos fundamentos da gestão sustentável (GS), ao passo que é influenciado diretamente pelos princípios de ética empresarial (EE), também conhecido como retidão social corporativa (RSC3). Principalmente na década de 1990, a ética empresarial foi incorporada como parte da avaliação das ações da diretoria das empresas em forma de governança corporativa (GC). Além disso, a RSC está fundamentada nos preceitos da teoria dos stakeholders, que traz consigo a ideia de ampliação dos limites organizacionais (boundary-spanning) (WADDOCK, 2004). A partir desse conceito a empresa não 
se concentra apenas em si mesma, mas passa a considerar o ambiente no qual está inserida. Com isso as empresas perceberam que ações irresponsáveis afetam negativamente sua reputação corporativa (RC2), fazendo-se necessário desenvolver uma nova forma de percepção dos anseios da sociedade e, por consequência, uma nova forma de mensurar os resultados obtidos.

A resposta para esses dois desafios está contida nos conceitos de responsividade social corporativa (RSC2) e performance social corporativa (PSC), respectivamente. O primeiro conceito fornece um caráter estratégico de prontidão da empresa na resposta às necessidades sociais (WADDOCK, 2004). A autora explica que a RSC2 exige que empresa crie formas ou até modifique sua estrutura no intuito de possibilitar o diálogo e a operacionalização das ações de cunho social. Um exemplo é a implementação de um 'disque-denúncia', que tem como função receber reclamações e denúncias anônimas sobre ações de funcionários, representantes e parceiros que tenham cometido atos de corrupção, de crime ecológico ou atividades ilegais (PALAZZO, 2002).

Já o conceito de PSC trata da avaliação dos resultados obtidos na implementação das estratégias de cunho social, que incluem os aspectos ético, ecológico e social, com base em medidas monetárias e não monetárias (HANSEN; SCHRADER, 2005). Como resultado final, pode-se analisar a empresa e afirmar em que nível de (ir)responsabilidade corporativa (RC1) ela se enquadra.

Em termos de objetivos, a RSC é entendida como sendo fundamentada na teoria de gestão sustentável, que por sua vez deriva da teoria de desenvolvimento sustentável (VAN MARREWIJK, 2003), e se apresenta, assim, como uma possibilidade instrumental para complementar o quadro da sustentabilidade em dois níveis distintos: nível dos negócios e nível societal.

A implementação da RSC no nível dos negócios tem como finalidade alcançar o status de 'empresa sustentável'. Para tanto, a implementação da RSC requer uma mudança na perspectiva da empresa de forma a incluir ações provenientes de uma reflexão estratégica de longo prazo, que se inicia a partir da análise dos resultados finais alcançados pela empresa, o que exige uma mudança da consciência dos gestores e funcionários. Assim, a empresa passa a trabalhar com base em uma nova lógica: ética-econômica, a partir da qual "há o comprometimento empresarial de, mesmo em momentos adversos, abdicar de ganhos de curto prazo, se isso significar prejuízos para o sistema como um todo" (KREIKEBAUM, 2000, p. 496).

Finalmente, conclui-se que o conceito de responsabilidade social corporativa não é um padrão estático, mas sim um processo contínuo na busca de níveis cada vez mais altos de envolvimento e comprometimento com os grupos sociais do seu ambiente. Essa ideia se apoia na definição formulada pelo WBCSD (2000, p.8, tradução livre) na qual RSC é entendida como:

“(...) um processo contínuo de comprometimento e de comportamento ético das empresas, visando contribuir com o desenvolvimento econômico ao mesmo tempo em que impulsiona a melhoria da qualidade de vida de seus funcionários e suas famílias, 0 bem-estar da comunidade local e da sociedade no seu conceito mais amplo".

O objetivo final da RSC é, portanto, o alcance do status de empresa sustentável, guiada por princípios econômicos, éticos e ecológicos, contribuindo assim para a consolidação de uma sociedade sustentável no nível societal. 


\section{DELIMITAÇÃO CONCEITUAL: RESPONSABILIDADE SOCIAL CORPORATIVA (RSC) VERSUS CIDADANIA COR- PORATIVA (CC)}

A confusão corrente dos significados e aplicações entre os conceitos de responsabilidade social corporativa e cidadania corporativa se deve em parte ao trabalho de Carroll. $\mathrm{O}$ autor publicou em 1998 um artigo com o título 'The Four Faces of Corporate Citizenship', sobre cidadania corporativa, utilizando o mesmo modelo que ele apresentou duas décadas antes para explicar os graus e critérios da RSC (CARROLL, 1979). Para Matten e Crane (2005, p.169) o termo cidadania corporativa, usado por Carroll, é mais acessível e atraente para o mundo dos negócios, haja vista que é mais fácil ser uma empresa "engajada" do que ser "responsável", o que explica o surgimento dessa nova nomenclatura.

No entanto, com o passar do tempo, é possível distinguir o significado de cada um desses dois conceitos. Por um lado, identifica-se na literatura a definição de cidadania corporativa como sinônimo de atividades de caridade e de trabalho voluntário, organizados e/ou patrocinados pelas empresas (MATTEN et al., 2003). Por outro lado, a cidadania corporativa é entendida, por alguns líderes econômicos e por alguns autores, como um termo que dá à empresa um novo caráter político (WADDOCK, 2004). Com isso, tem-se aqui uma expansão do conceito de CC, a qual Matten et al. (2003, p.114) denominam "visão ampliada" da cidadania corporativa.

Nesse sentido, a função central da CC passa a ser a inserção da empresa na arena da cidadania, de modo a suprir a sociedade no tocante a aspectos sociais quando o governo não o faz, ou então o faz de forma ineficiente e/ou precária (MATTEN et al., 2003). Na prática, a empresa passa a cooperar e tomar parte na solução dos problemas sociais que, em princípio, é de responsabilidade do poder público (SCHNEIDER; STEINER, 2004). Além disso, a partir desse conceito de CC, a empresa passa a ser uma disseminadora e guardiã dos princípios humanitários - descritos pelo Global Compact - na esfera internacional e no que se refere às ações que busquem assegurar a preservação do meioambiente, a observação de normas do trabalho, defesa dos direitos humanos e combate à corrupção (HANSEN; SCHRADER, 2005).

Com o termo "cidadania" pode ser entendido que a empresa passa a ocupar um espaço na sociedade ao lado de outros atores sociais, já que "ser cidadão" implica em ter direitos e deveres tal como os demais (MATTEN et al., 2003). Contudo, a transposição dessa terminologia para a esfera corporativa não é automática, mesmo que esse conceito pareça lógico e simples de ser implementado. Matten e Crane (2005) argumentam que o termo cidadania corporativa é inadequado para designar a função social das empresas, haja vista que estas não desempenham um papel igual aos cidadãos normais, mas sim um tipo especial de cidadania. A tese central é de que não significa que as empresas "sejam" cidadãs, ou que "tenham" cidadania, mas certamente possuem um "papel ativo" em sua manutenção e também exibem [ou não] comportamentos adequados e esperados pelos cidadãos (MATTEN et al., 2003, p.115).

Como mencionado anteriormente, verifica-se que, na prática, o termo cidadania corporativa é sinônimo de trabalho desenvolvido pela empresa conjuntamente com a sociedade civil organizada (HANSEN; SCHRADER, 2005). Essas ações comunitárias englobam: (1) doações (de material, de equipamentos ou em espécie); (2) trabalho voluntário (liberação de funcionários, programas de assessoria a conselhos comunitários, etc.); (3) ações mistas que envolvam esses dois aspectos ('apadrinhamento' de praças, escolas, etc.). Essas ações são facilmente reconhecidas pela comunidade e podem servir de 'pano de fundo' de campanhas publicitárias, já que filantropia se vende facilmente como atividades de 'relações públicas', ou seja, as empresas acabam agindo em interesse próprio (MATTEN et al., 2003). 
As ações de cunho filantrópico têm vinculação com a dimensão social do conceito de RSC (MAIGNAN; FERRELL, 2000). Contudo, elas podem ser enquadradas em duas abordagens diferentes de filantropia: (1) puramente caritativas e; (2) como 'filantropia estratégica' (PORTER; KRAMER, 2002). No primeiro caso, envolve ações que objetivam à melhoria de lugares públicos na vizinhança da empresa e/ou ao patrocínio de eventos comunitários. No segundo caso, consiste em programas desenvolvidos pela empresa que tenham ligação direta com o seu negócio (ex.: financiamento de grupos de pesquisas universitárias que podem ser revertidas em produtos ou tecnologias) ou que possam repercutir positivamente no aumento da produtividade ou do desempenho geral da empresa (ex.: formação complementar e treinamento dos funcionários, manutenção de creches para filhos de trabalhador melhorias físicas no ambiente de trabalho).

Por fim, pode-se afirmar que o conceito de CC comporta a ideia de pertencimento e efetiva participação da empresa em seu meio imediato contemplando os interesses comunitários. Por sua vez, o conceito de RSC tem por base a responsabilidade de considerar conjuntamente em suas estratégias, decisões e ações aspectos que atendam a parâmetros econômicos, incluam padrões ecológicos sustentáveis, éticos - principalmente no que se refere aos clientes e aos funcionários - e que também atendam à comunidade. De forma resumida, verifica-se que o conceito de RSC possui um espectro mais amplo do que o de CC.

\section{QUADRO CONCEITUAL COMPARATIVO PARA DELIMI- TAÇÃO DE RSC}

Durante a discussão sobre RSC fica clara a necessidade de comparar e evidenciar as relações e delimitações teóricas entre os conceitos-chave abordados até aqui. Nesse sentido, foi construído um quadro comparativo para delimitar, em termos teóricos, os conceitos correlatos e concorrentes do constructo RSC (Quadro 3). Para tanto, foram escolhidos quatro critérios: orientação prioritária, nível de implementação na empresa, abordagem principal e stakeholders preferenciais.

Cada critério foi individualmente classificado em três possíveis níveis, em função de sua importância teórica, em: alta, média e baixa. Na sequência, procedeu-se a uma análise comparativa para encontrar pontos em comum e/ou divergentes entres os conceitos-chave e a RSC (Veja Quadro 3). Essa análise teórica está fundamentada principalmente nos estudos de Carroll $(1979 ; 1991 ;$ 1998), Maignan e Ferrell (2000), Kreikebaum et al. (2001), EU-Kommission (2001), Rodriguez et al. (2002), Suchanek (2003), Van Marrewijk (2003), Matten et al. (2003), Schneider e Steiner (2004), Homann (2004), Waddock (2004), Hansen e Schrader (2005), Clarkson (1995), Donaldson e Preston (1995), Matten e Crane (2005), os quais representam trabalhos relevantes sobre o tema.

\begin{tabular}{|c|c|c|c|c|c|c|c|c|}
\hline & & \multirow{2}{*}{\multicolumn{7}{|c|}{ Conceitos-chave }} \\
\hline & & & & & & & & \\
\hline & & RSC1 & RSC2 & $\mathrm{EE}$ & GC & CC & RC2 & PSC \\
\hline \multicolumn{2}{|c|}{ Critérios } & & & & & & & \\
\hline & & & & & & & & \\
\hline \multirow{5}{*}{$\begin{array}{l}\text { Orientação } \\
\text { prioritária }\end{array}$} & Ética & $\bullet$ & $\bullet$ & $\bullet$ & $\bullet$ & $\bullet$ & $\not x$ & $\not a$ \\
\hline & Econômico & $x$ & $i$ & $i$ & $\not$ & $\not x$ & $\bullet$ & $\bullet$ \\
\hline & Ecológico & $\bullet$ & $\bullet$ & $\bullet$ & $i$ & & $\mathrm{i}$ & $\not x$ \\
\hline & Social & $\bullet$ & $\bullet$ & $\not a$ & $\not$ & $\bullet$ & $\mathrm{i}$ & $\bullet$ \\
\hline & Filantrópico & i & $\mathrm{i}$ & $\mathrm{i}$ & i & - & $\not$ & $\mathrm{i}$ \\
\hline
\end{tabular}




\begin{tabular}{|c|c|c|c|c|c|c|c|c|}
\hline \multirow{3}{*}{$\begin{array}{l}\text { Nível de imple- } \\
\text { mentação na } \\
\text { empresa }\end{array}$} & Estratégico & $\bullet$ & $\bullet$ & $\bullet$ & i & $\mathrm{i}$ & $\not a$ & $\bullet$ \\
\hline & Tático & $\not a$ & $\not a$ & $\not a$ & $\bullet$ & $\not a$ & $\bullet$ & $\not a$ \\
\hline & Operacional & $\mathrm{i}$ & $\mathrm{i}$ & $\mathrm{i}$ & $\not$ & $\bullet$ & $\mathrm{i}$ & $\mathrm{i}$ \\
\hline \multirow{3}{*}{$\begin{array}{c}\text { Abordagem } \\
\text { principal }\end{array}$} & Normativo & $\bullet$ & $\mathrm{i}$ & $\not a$ & $\not a$ & $\bullet$ & $\mathrm{i}$ & $\mathrm{i}$ \\
\hline & Descritivo & $\not a$ & $\not a$ & $\bullet$ & $\bullet$ & & $\not a$ & a \\
\hline & Instrumental & i & $\bullet$ & $\mathrm{i}$ & $\mathrm{i}$ & $\not$ & - & 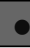 \\
\hline \multirow{6}{*}{$\begin{array}{l}\text { Stakeholders } \\
\text { preferenciais }\end{array}$} & Funcionários & $\bullet$ & $\bullet$ & $\not a$ & $\not a$ & $\bullet$ & b & $\not$ \\
\hline & Diretoria & $\mathrm{i}$ & $\not$ & $\bullet$ & $\bullet$ & . & $\bullet$ & $\bullet$ \\
\hline & Comunidade & $\not a$ & $\bullet$ & i & i & $\bullet$ & $\not a$ & $\not a$ \\
\hline & Fornecedores & $\not a$ & i & $\not a$ & $\not a$ & $\not a$ & $\mathrm{i}$ & $\mathrm{i}$ \\
\hline & Acionistas & $\mathrm{i}$ & $\mathrm{i}$ & $\bullet$ & $\bullet$ & & $\bullet$ & $\bullet$ \\
\hline & Clientes & $\bullet$ & a & a & i & $\not$ & $\bullet$ & $\bullet$ \\
\hline
\end{tabular}

- alta importância

$\odot$ média importância

baixa importância

Divergências teóricas significativas em comparação ao conceito de RSC

Quadro 3: Quadro conceitual comparativo para delimitação de RSC

Fonte: Elaborado pelos autores.

A escolha do primeiro critério, 'orientação prioritária', tem como base os pilares de sustentação conceitual da teoria de gestão sustentável (RODRIGUEZ et al., 2002; MÜLLER-CHRIST, 2004; HÜLSMANN, 2004), ou seja, a tríade de sustentabilidade engloba as dimensões econômicas, ecológicas e sociais. No intuito de aprimorar essa classificação, foram acrescentadas as dimensões ética e filantrópica devido à sua relevância e disseminação, respectivamente, na construção do conceito de RSC (CARROLL, 1979, 1991, 1998; MAIGNAN; FERRELL, 2000; KREIKEBAUM, 2000; SCHNEIDER; STEINER, 2004; HOMANN, 2004). Cabe esclarecer que há uma sexta orientação, a legal, a qual se refere ao atendimento e cumprimento de leis, normas e regulamentos, que não foi utilizada para delimitar a RSC por ser entendida como condição igualmente elementar para todos os constructos aqui analisados.

O segundo critério, 'nível de implementação na empresa', deriva da teoria de gestão estratégica (RODRIGUEZ et al., 2002; MÜLLER-CHRIST, 2004; HÜLSMANN, 2004). A partir desse critério, enquadra-se cada conceito mediante o grau de importância na implementação das estratégias sociais nas empresas segundo três níveis: estratégico, tático e operacional (ANSOFF, 1977; PORTER, 1986; GHEMAWAT, 2000).

O terceiro critério, 'abordagem principal', representa as abordagens teóricas encontradas na literatura - apresentadas no Quadro 2 - que tratam da temática dos negócios e sociedade (DONALDSON; PRESTON, 1995; RODRIGUEZ et al., 2002; MATTEN et al., 2003; HOMANN, 2004; SUCHANEK, 2003; WADDOCK, 2004).

A relevância da teoria de gestão de stakeholders está consolidada no quarto critério (FREEMAN, 1984; DONALDSON; PRESTON, 1995; CLARKSON, 1995). Os seis grupos de interesse relacionados no Quadro 3 foram escolhidos, devido à frequência de suas citações, como de suma importância para praticamente qualquer empresa, independentemente do ramo de atividade, tamanho ou faturamento (DAVIS; FREDERICK, 1985). O governo, apesar de não ter sido citado, compreende um sétimo e significativo stakeholder. No entanto, sua relevância e influência são paritárias para todos os conceitos aqui discutidos, ou seja, seria redundante utilizá-lo como critério de análise. 
No Quadro 3 fica clara a delimitação entre os conceitos de RSC, de governança corporativa (GC) e de reputação corporativa (RC2), principalmente ao tomar como base os critérios de 'orientação prioritária' e 'stakeholders preferenciais'. Esse fato era esperado porque, de acordo com a literatura pesquisada, esses são os conceitos que menos se confundem com o de RSC (RABELO; VASCONCELOS, 2002; SCHNEIDER, 2004). O ponto mais importante que eles têm em comum é o fato dos clientes ocuparem uma posição de destaque na implementação e consolidação das estratégias voltadas para os stakeholders.

De forma geral, os critérios de 'abordagem principal' e 'stakeholders preferenciais' se apresentam como fortemente representativos na delimitação conceitual entre RSC e seus conceitos-chave. No tocante à abordagem principal, verifica-se uma diferenciação entre RSC e os conceitos de responsividade social corporativa (RSC2), performance social corporativa (PSC) e RC2. A explicação disso é o pragmatismo inerente a esses conceitos, pois os três - RSC2, PSC e RC2 objetivam a investigar os benefícios que a empresa terá caso se comporte de forma responsável. A RSC, por sua vez, possui um caráter normativo de obrigação moral em relação aos stakeholders (SUCHANEK, 2003; HOMANN, 2004).

O quarto critério, stakeholders preferenciais, evidencia a distinção entre os conceitoschave de ética empresarial (EE), GC, RC2 e PSC face ao de RSC. Enquanto que para a EE e a GC os principais grupos de interesses a serem considerados são a diretoria e os acionistas - stakeholders que também são importantes para RC2 e o PSC-, a RSC prioriza os funcionários e os clientes. Esse último grupo de stakeholders tem importância primordial também para RC2 e PSC.

A delimitação conceitual entre RSC e cidadania corporativa (CC) é evidenciada pelos critérios de orientação prioritária e pelo nível de implementação na empresa. Tendo por base a análise do Quadro 3, fica evidente que ambos os conceitos são fortemente fundamentados nas dimensões éticas e sociais. Entretanto, enquanto que para a RSC a filantropia desempenha um papel secundário, no caso da CC ela representa o terceiro pilar de sua sustentação, tendo em vista que o engajamento comunitário fica em primeiro plano. Em relação ao nível na estrutura da empresa que CC e RSC ocupam, é visível que a RSC se posiciona como um conceito de natureza estratégica, enquanto que a CC é enquadrada no nível operacional.

De modo geral, verifica-se que em todos os conceitos-chave a orientação ética é tida como importante, enquanto que a orientação filantrópica possui uma importância pouco expressiva para a maioria dos conceitos. Em relação ao nível de implementação na empresa, fica evidente que a maioria dos conceitos-chave não é percebida como operacionais. Finalmente, constata-se que, entre os seis principais stakeholders, os fornecedores aparecem como preocupação secundária na literatura sobre RSC mesmo sendo parte integrante do framework definido pela WBCSD (2000).

\section{CONSIDERAÇÕES FINAIS}

A literatura acerca da temática de negócios e sociedade apresenta conceitos correlatos ao de responsabilidade social corporativa que muitas vezes são empregados como seus sinônimos. Isso acontece com frequência principalmente no que se refere aos conceitos de responsividade social, ética empresarial e cidadania corporativa, apesar desses conceitos se diferenciarem em termos de conteúdo, abordagens e níveis em que são implementados nas empresas. No presente artigo essas diferenças foram apresentadas e discutidas. Para tanto, primeiramente foram abordadas as principais contribuições teóricas advindas de campos do conhecimento distintos e importantes na evolução do conceito de RSC. 
Como contribuições para o avanço do debate sobre a temática de negócios e sociedade, em especial a RSC, conclui-se ser este um conceito amplo e interdisciplinar, o qual exige uma dinâmica própria que represente o inter-relacionamento e o caráter complementar entre os conceitos-chave que dão forma ao complexo processo de implementação de RSC (Veja fig. 4). Com base no modelo da dinâmica interdisciplinar da RSC foi possível concretizar seus objetivos em nível dos negócios e na esfera societal. No primeiro caso, a RSC é compreendida como uma pedra fundamental da implementação de uma empresa sustentável. Em relação ao nível societal, fica claro o papel fundamental desempenhado pela RSC para o alcance de uma sociedade sustentável.

Adicionalmente, foram apresentadas resumidamente três principais delimitações conceituais entre RSC e os demais conceitos-chave que tratam do envolvimento empresarial nas questões sociais. Primeiramente, destaca-se o fato de que a RSC possui um caráter estratégico dentro da empresa, enquanto que GC, CC, e RC2 tendem a ser enquadrados no nível tático. Em segundo lugar, a RSC prima pelo balanceamento entre o desempenho econômico e os preceitos éticos, ecológicos e sociais, além da evidente observância dos requisitos legais. Já para conceitos de $\mathrm{EE}$ e de RSC2, o argumento ético está em primeiro plano. Em terceiro, o conceito de RSC prioriza preferencialmente as expectativas tanto dos funcionários e dos clientes, enquanto que para a EE, GC, RC2 e PSC o foco na diretoria e nos acionistas é prioritário, assim como a comunidade local é parte principal da abordagem dos conceitos de RSC2 e CC.

As limitações apontadas neste estudo são circunscritas: a) à escolha que originou o recorte teórico que ainda pode ser ampliado e/ou confrontado com outras abordagens; b) à necessidade de aplicação do modelo teórico da dinâmica interdisciplinar de RSC. Assim, sugere-se para futuras pesquisas empíricas do modelo proposto, considerando diversos tipos de organizações, ramos de atividade distintos e diferentes tamanhos.

\section{REFERÊNCIAS}

ANSOFF, H. Estratégia empresarial. São Paulo: McGraw-Hill do Brasil, 1977.

CARROLL, A. B. A Three-Dimensional Conceptual Model of Corporate Performance. Academy of Management Review. Vol.4, n.4, p. 497-505, out-dez. 1979.

.The Pyramid of corporate social responsibility: Toward the moral management of organizational stakeholders. Business Horizons. Vol. 34, n. 4, p. 39-48, 1991.

The Four Faces of Corporate Citizenship. Business and Society Review. Vol.100, n.101, p.1-7, 1998.

CLARKSON, M.B.E. A Stakeholder Framework for Analysing und Evaluating Corporate Social Performance. Academy of Management Review. Vol. 20, n.1, p.92-117, 1995.
DAVIS, K.; FREDERICK, W.C. Business and Society: management, public policy, ethics. 5.ed. Singapore: McGraw-Hill, 1985.

DAVIS, K. The case for and against business assumptions of social responsibilities. Academy of Management Journal. Vol. 16, n.2, p.312-322. 1973.

DONALDSON, T.; PRESTON, L.E. The Stakeholder Theory of the Corporation: Concepts, Evidence, and Implications. Academy of Management Review. Vol. 20, n.1, p.65-91, 1995.

ENDERLE, G.; TAVIS, L.A. A balanced concept of the firm and the measurement of its longterm planning and performance. Journal of Business Ethics.Vol.17, p.1129-1144,1998.

EU-KOMMISSION. Grünbuch Europäische Rahmenbedingungen für die soziale Verantwortung der Unternehmen, KOM (2001) 366 endgültig, 18.7.2001, Brüssel, 2001. 
FREDERICK, W.C. Theories of Corporate social Performance. In: SETHI, S.P./FLABE, C.M. Business and Society - Dimensions of Conflict and Cooperation. New York. Lexington Books. p.142-161. 1987.

FRIEDMAN, M. Capitalismo e Liberdade. São Paulo: Nova Cultural, 1988.

FREEMAN, R. E. Strategic Management: A Stakeholder Approach. Boston: Pitmann, 1984.

GARRIGA, E.; MELÉ, D. Corporate Social Responsibility Theories: Mapping the Territory. Journal of Business Ethics. Vol. 53, p.51-71. 2004.

GHEMAWAT, P. A estratégia e o cenário de negócios. Porto Alegre: Bookman, 2000.

HANSEN, U. Gesellschaftliche Verantwortung der Unternehmen. In: SCHNEIDER, U.; STEINER, P. (Hrsg). Betriebswirtschaftslehre und gesellschaftliche Verantwortung: mit Corporate Social Responsibility zu mehr Engagement. Wiesbaden: Gabler, p.59-83, 2004.

HANSEN, U.; SCHRADER, U. Corporate Social Responsibility als aktuelles Thema der Betriebswirtschaftslehre. Die Betriebswirtschaft. Vol.65, n.4, p.373-395, 2005.

HOMANN, K. Gesellschaftliche Verantwortung als Business Case. In: SCHNEIDER, U.; STEINER, P.(Hrsg). Betriebswirtschaftslehre und gesellschaftliche Verantwortung: mit Corporate Social Responsibility zu mehr Engagement. Wiesbaden: Gabler, p.1-16, 2004.

HÜLSMANN, M. Bezugspunkte zwischen Strategischem Management und Nachhaltigkeit. In:Hülsmann, M.; Müller-Christ, G.;Haasis, H.D.(Hrsg.).Betriebswirtschaftslehre und Nachhaltigkeit: Bestandaufnahme und Forschungsprogrammatik. Wiesbaden: Deutscher Universitäts-Verlag, p. 25-72, 2004.

ISO SURVEY 2005. Disponível em: http:// www.iso.org/iso/en/iso9000-14000/pdf/ survey2005.pdf. Acesso em: 15.11.2006.

JOYNER, B.E.; PAYNE, D. Evolution and implementation: a study of values, business ethics and corporate social responsibility. Journal of Business Ethics. Vol. 41, p.297-311. 2002.

KREIKEBAUM, $\mathrm{H}$. Unternehmens- und Produktethik. In: SCHNEIDER, H. (Hrsg.). Produktionsmanagement in kleinen und mittleren Unternehmen. Stuttgart: SchäfferPoeschel, p.488-503, 2000.

KREIKEBAUM, H.; BEHNAM, M.; GILBERT, D.U. Management ethischer Konflikte in international tätige Unternehmen. Wiesbaden: Gabler, 2001.

MAIGNAN, I.; FERRELL, O.C. Measuring Corporate Citizenship in Two Countries: The Case of the United States and France. Journal of Business Ethics. Vol. 23, p.283-297, 2000.

MATTEN, D.; CRANE, A. Corporate Citizenship: Toward an Extended Theoretical Conceptualization. Academy of Management Review. Vol. 30, n.1, p.166-179, jan. 2005.

MATTEN, D.; CRANE, A.; CHAPPLE, W. Behind the Mask: Revealing the True Face of Corporate Citizenship. Journal of Business Ethics. Vol. 45, p.109-120, 2003.

MÜLLER-CHRIST, G. Auch Unternehmen selbst müssen nachhaltig werden. In: Hülsmann, M.; Müller-Christ, G.; Haasis, H.D. (Hrsg.). Betriebswirtschaftslehre und Nachhaltigkeit: Bestandaufnahme und Forschungsprogrammatik. Wiesbaden: Deutscher Universitäts-Verlag, p. 3-24, 2004.

NAOR, J. A New Approach to Multinational Social Responsibility. Journal of Business Ethics. Vol. 1, p.219-225. 1982.

PALAZZO, B. U.S.-American and German Business Ethics - An Intercultural Comparison. Journal of Business Ethics. Vol. 41, p.195-216. 2002. 
PORTER, Michael E.; KRAMER, Mark R. The Competitive Advantage of Corporate Philanthropy. Harvard Business Review, p. 5668, dec. 2002.

PORTER, M. Estratégia competitiva: técnicas para análise de indústrias e da concorrência. Rio de Janeiro: Campus, 1986.

PRESTON, L.E.; POST, J.E. Private Management and Public Policy. California Management Review. Vol.23, n.3, p.56-63. 1975.

QUAZI, A. M.; O'BRIEN, D. An empirical test of a cross-sectional model of corporate social responsibility. Journal of Business Ethics. Vol. 25p. 33-51. 2000.

RABELO, F.M.; VASCONCELOS, F.C. Corporate Governance in Brazil. Journal of Business Ethics. Vol.37, p.321-335, 2002.

RNE (RAT FÜR NACHHALTIGE ENTWICKLUNG). Unternehmerische Verantwortung in einer globalisierten Welt: ein deutsches Profil der Corporate Responsibility. Empfehlungen des Rates für Nachhaltige Entwicklung. Berlin, 17.09.2006.

RODRIGUEZ, M.A.; RICART, J.E.; SANCHEZ, P. Sustainable Development and the Sustainability of competitive advantage: a dynamic and sustainable view of the firm. Creativity and Innovation Management. Vol.11, n.3, p.135146, 2002.

SAI - SOCIAL ACCOUTABILITY INTERNATIONAL. Soziale Verantwortung 8000 - Social Accountablility 8000. Disponível em: http:// www.sa-intl.org/index.cfm. Acesso em: 17.11.06.

SCHWARTZ, M.S.; CARROLL, A.B. Corporate Social Responsibility - a three-domain approach. Business Ethics Quarterly. Vol.13, n.4, p. 503-530. 2003.

SCHNEIDER, U. Governance statt Government? In: SCHNEIDER, U.; STEINER, P. (Hrsg). 2004. Betriebswirtschaftslehre und gesellschaftliche
Verantwortung: mit Corporate Social Responsibility zu mehr Engagement. Wiesbaden: Gabler, p. 17-44, 2004.

SCHNEIDER, U.; STEINER, P. (Hrsg). Betriebswirtschaftslehre und gesellschaftliche Verantwortung: mit Corporate Social Responsibility zu mehr Engagement. Wiesbaden: Gabler, 2004.

SETHI, S.P. Dimensions of Corporate Social Performance - an Analytical Framework. California Management Review. Vol.17, n.3, p. 58-65. 1975.

SEVERINO, A. J. Metodologia do trabalho científico. 21. ed. São Paulo: Cortez, 2000.

SUCHANEK, A. Ökonomische Unternehmensethik. Diskussionsbeiträge der Katholischen Universität Eichstätt-Ingolstadt. Nr. 166, p.1-22, 2003.

VAN MARREWIJK, M. Concepts and Definitions of CSR and Corporate Sustainability: Between Agency and Communion. Journal of Business Ethics. Vol. 44, p. 95-105, 2003.

WADDOCK, S. Parallel Universes: Companies, Academics, and the Progress of Corporate Citizenship. Business and Society Review. Vol. 109, n.1, p.5-42, 2004.

WARTICK, S.; COCHRAN, P.L. The Evolution of Corporate Social Performance Model. Academy of Management Review. Vol. 29, n.1, p.124-132. 1985.

WBCSD (WORLD BUSINESS COUNCIL FOR SUSTAINABLE DEVELOPMENT). Corporate Social Responsibility: making good business sense. Genf. Jan. 2000.

WECD (World Commission on Enviroment and Development). Our Common Future, 1987.

WOOD, D.J. Corporate social performance revisited. Academy of Management Review. Vol. 16, n.4, p.691-718, 1991. 
WHETTEN, D. A. Desenvolvimento de teoria. O que constitui uma contribuição teórica? RAE Revista de Administração de Empresas, São Paulo, v. 43, n. 3, p. 69-73, 2003.

ZENISEK, T.S. Corporate Social Responsibility. A conceptualization on organizational literature. Academy of Management Review. Vol. 4, n.3, p. 359-368. 1979. 